\title{
Hollow $\mathrm{NiCo}_{2} \mathrm{O}_{4}$ Nanofibers as Sulphur Host Materials for High-Performance Lithium-Sulphur Batteries
}

\author{
Yunfeng Lin $^{1,2, *}$, Yigao Miao ${ }^{1,2}$ \\ ${ }^{1}$ Lishui University, Lishui, Zhejiang, 323000, China. \\ ${ }^{2}$ Key Laboratory of Digital Design and Intelligent Manufacturing for Creative Cultural Products of \\ Zhejiang Province, Lishui, Zhejiang, 323000, China. \\ *E-mail: yunfenglinzj@ tom.com
}

doi: $10.20964 / 2020.05 .50$

Received: 3 January 2020 / Accepted: 2 February 2020 / Published: 10 April 2020

\begin{abstract}
Cobaltate plays an important role in many applications, such as photocatalysis and water purification. However, few works have reported about the employment of cobaltate in energy storage systems. As we all know, the lithium-sulfur batteries suffer from severe capacity fade during the electrochemical cycles due to the shuttle effect of the polysulfide products. In our work, we design hollow $\mathrm{NiCo}_{2} \mathrm{O}_{4}$ nanofibers as host materials for elemental sulfur in lithium-sulfur batteries. The unique hollow nanofiber structure could provide sufficient space for the storage of the soluble polysulfide and inhibit the migration of the polysulfide products. Moreover, the chemical bond of $\mathrm{Ni}-\mathrm{S}$ is proved to exist after electrochemical cycles, demonstrating chemical relationship between the $\mathrm{NiCo}_{2} \mathrm{O}_{4}$ and soluble polysulfide. As a result, the as-prepared hollow $\mathrm{NiCo}_{2} \mathrm{O}_{4}-\mathrm{S}$ composites exhibit high capacity and excellent cycling stability.
\end{abstract}

Keywords: Cobaltate, Polysulfide, Li-S battery, Migration, Capacity

\section{$\underline{\text { FULL TEXT }}$}

(C) 2020 The Authors. Published by ESG (www.electrochemsci.org). This article is an open access article distributed under the terms and conditions of the Creative Commons Attribution license (http://creativecommons.org/licenses/by/4.0/). 